Supporting Information for:

\title{
Altering the Folding Patterns of Naphthyl Trimers
}

\author{
Gregory J. Gabriel, Steven Sorey and Brent L. Iverson* \\ Department of Chemistry and Biochemistry \\ The University of Texas at Austin \\ Austin, TX 78712 \\ biverson@mail.utexas.edu
}

\author{
Contents: \\ S2 Chemical structures and cartoon representations \\ S3 General methods for synthesis \\ S3 NMR spectroscopy methods \\ S4 Compound characterization and NOESY spectra \\ S7 UV-Vis methods and data table \\ S7 Molecular modeling methods
}




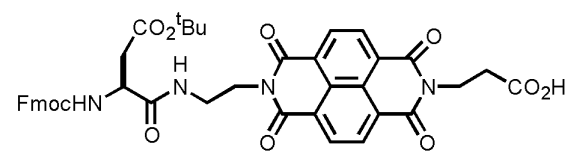

FmocNH-Asp( $\left.{ }^{t} \mathrm{Bu}\right)-\mathrm{Ndi}-\mathrm{OH}$

Fmoc $=9$-fluoronylmethyloxycarbonyl

$A s p\left(O^{t} \mathrm{Bu}\right)=$ tert-butyl protected aspartic acid residue<smiles>CC(C)(C)Oc1cccc2c(OCCCNC(=O)C(CC(=O)O)NCCF)cccc12</smiles>

FmocNH-Asp(Ot $\left.{ }^{t} \mathrm{Bu}\right)-\mathrm{Dan}^{(\mathrm{n})}-\mathrm{OH}$

Ndi $=1,4,5,8$-naphthylene-tetracarboxylic diimide moiety Dan $=1,5$-dialkoxy-naphthylene moiety

Figure 1S. Amino acid adducts used for solid phase peptide synthesis, $n=1$ or 3 .<smiles>[Y1]COc1ccc(I)c2c(OCCCNC(=O)[C@@H](CC)NC(=O)O)cccc12</smiles>

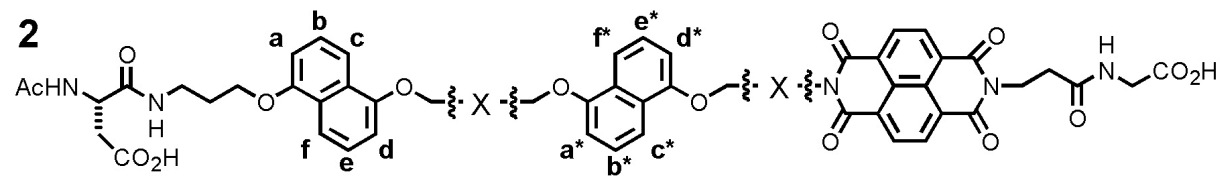

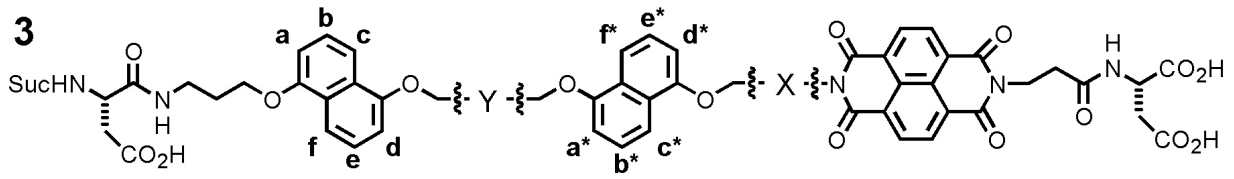<smiles>[Y1]COc1cccc2c(OCCCC(=O)NCO)cccc12</smiles>

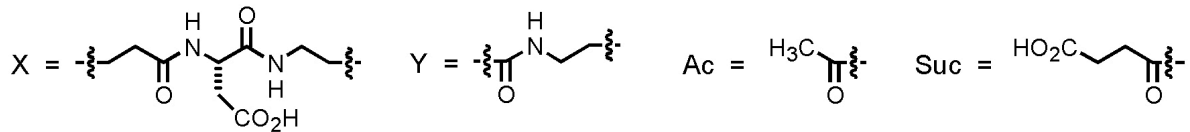

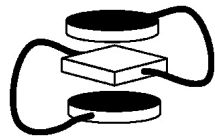

1

Pleated

folding

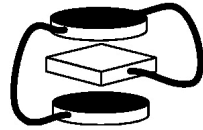

2

Intercalative folding

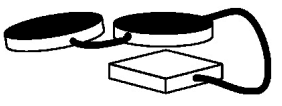

3

Trimer stacking prevented

Figure 2S. Naphthyl trimers $1-3$ and dimer 4 synthesized for this study. Labeled a-f and a*-f* are the Dan and Dan* aromatic proton designations used for NOESY analyses. Cartoon representations of the proposed solution conformations are also shown. 
Synthesis of 1-4. The synthesis of the amino acid adducts in figure $1 \mathrm{~S}$ was previously reported and the synthesis of FmocNH-Asp $\left(\mathrm{O}^{t} \mathrm{Bu}\right)-\mathrm{Dan}^{(\mathrm{n}=1)}-\mathrm{OH}$ followed a modified procedure using $\mathrm{BrCH}_{2} \mathrm{CO}_{2}{ }^{\mathrm{t}} \mathrm{Bu}$ as the O-alkylaing agent (Zych, A. J.; Iverson, B. L. J. Am. Chem. Soc. 2000, 122, 8898). General methods, full protocols for solid phase peptide synthesis and FPLC/HPLC purification used for oligomers 1-4 in figure $2 \mathrm{~S}$ were detailed previously as well (Gabriel, G. J.; Iverson, B. L. J. Am. Chem. Soc. 2002, 124, 15174).

Compound characterization (1D-NMR general methods). Synthesis, followed by purification, desalting, and freeze drying afforded soft pale purple solids for all compounds. Samples were readily soluble in $50 \mathrm{mM}$ sodium phosphate, $\mathrm{pH}=7.0 \mathrm{D}_{2} \mathrm{O}$. Spectra were recorded on a Varian INOVA $500 \mathrm{MHz}$ spectrometer at $1 \mathrm{mM}$ concentrations of compound and TSP- $d_{4}$ (3trimethylsilyl-propionic-2,2,3,3- $d_{4}$ acid, sodium salt) was used as a reference $(\delta=0.00 \mathrm{ppm})$. Chemical shifts reported in ppm and abbreviations used are singlet (s), doublet (d), doublet of doublet $(\mathrm{dd})$, triplet $(\mathrm{t})$, quartet $(\mathrm{q})$, multiplet $(\mathrm{m})$ and complex multiplet of non-equivalent protons (comp). J coupling constants $(J)$ reported in $\mathrm{Hz}$.

NOESY and TOCSY spectroscopy (2D-NMR general methods). Steven Sorey performed all 2D-spectra acquisitions. For proton assignment purposes a total of four 2D-NMR spectra were taken, all at $1 \mathrm{mM}$ concentrations of compound in sodium phosphate buffered solvents as before. Samples in $90 / 10$ buffered $\mathrm{H}_{2} \mathrm{O} / \mathrm{D}_{2} \mathrm{O}$ were prepared for NOESY spectra which were acquired at two different mixing times of 200 and 800 milliseconds. NOESY techniques were not useful in correlating one side of a Dan residues (protons $\mathrm{a}, \mathrm{b}$ and $\mathrm{c}$ in figure $2 \mathrm{~S}$ ) with the other side (protons d, e and f) making it seem exceedingly difficult to "walk" from one end of the oligomer to the other. Fortunately TOCSY methods have been developed for aromatic systems that can make through-bond connections between protons a and $\mathrm{d}$ on naphthyl groups for example (Martin, G.E.; Crouch, R.C. in Two-Dimensional NMR Spectroscopy; Croasmun, W. R.; Carlson, R. M., Eds; VCH Publishers: New York, 1994). TOCSY spectra were thus taken in 100\% buffered $\mathrm{D}_{2} \mathrm{O}$ also at two different mixing times, 50 and 150 milliseconds.

Informative NOEs were observed between the Dan and Ndi units when NOESY spectra were taken in $100 \% \mathrm{D}_{2} \mathrm{O}$ with a mixing time of 800 milliseconds. The spectra, shown in figures 3S-5S, clearly indicate through-space $\mathrm{H}-\mathrm{H}$ contacts between the Ndi unit and Dan rings. SPARKY, an online visualization program, facilitated the imaging and interpretation of 2D-NMR spectra (Goddard, T. D.; Kneller, D. G. SPARKY version 3.85, University of California, San Francisco 2000). 
“AcHN-AspDanAspNdiAspDan*Gly-OH " (1). (91\% yield) ${ }^{1} \mathrm{H}$ NMR (500 MHz, $\left.\mathrm{D}_{2} \mathrm{O}\right) \delta=$ $8.04(\mathrm{q}, J=10.0$ and $7.6,4 \mathrm{H}), 7.22(\mathrm{~d}, J=8.4,2 \mathrm{H}), 6.97-6.94(\mathrm{comp}, 6 \mathrm{H}), 6.92(\mathrm{~d}, J=8.0,2 \mathrm{H})$, 6.86 (t, $J=7.6,2 \mathrm{H}), 6.82$ (t, $J=7.6,2 \mathrm{H}), 6.72$ (d, $J=8.4,2 \mathrm{H}), 6.54-6.53$ (comp, 4H), 6.34-6.30 (comp, 4H), 4.72 (dd, $J=5.6$ and 2.2, 1H), 4.63 (dd, $J=5.4$ and 2.4, 1H), 4.52 (dd, $J=5.0$ and $3.8,1 \mathrm{H}), 4.37-4.33(\mathrm{~m}, 1 \mathrm{H}), 4.29-4.23(\mathrm{~m}, 2 \mathrm{H}), 4.16-4.13(\mathrm{~m}, 1 \mathrm{H}), 4.02-4.01(\mathrm{~m}, 2 \mathrm{H}), 3.93-3.91$ (m, 2H), 3.83-3.52 (comp, 9H), 3.49 (t, $J=6.8,2 \mathrm{H}), 3.41-3.38(\mathrm{~m}, 1 \mathrm{H}), 2.78-2.74(\mathrm{~m}, 2 \mathrm{H}), 2.72-$ 2.51 (comp, 6H), 2.45 (t, $J=7.4,2 \mathrm{H}), 2.42-2.37$ (m, 2H), 2.10-1.96 (comp, 8H), 1.94 (s, 3H); ESI MS calcd for $\mathrm{C}_{69} \mathrm{H}_{74} \mathrm{~N}_{9} \mathrm{O}_{23}[\mathrm{M}]^{+} 1396.49$, found 1396.48 .

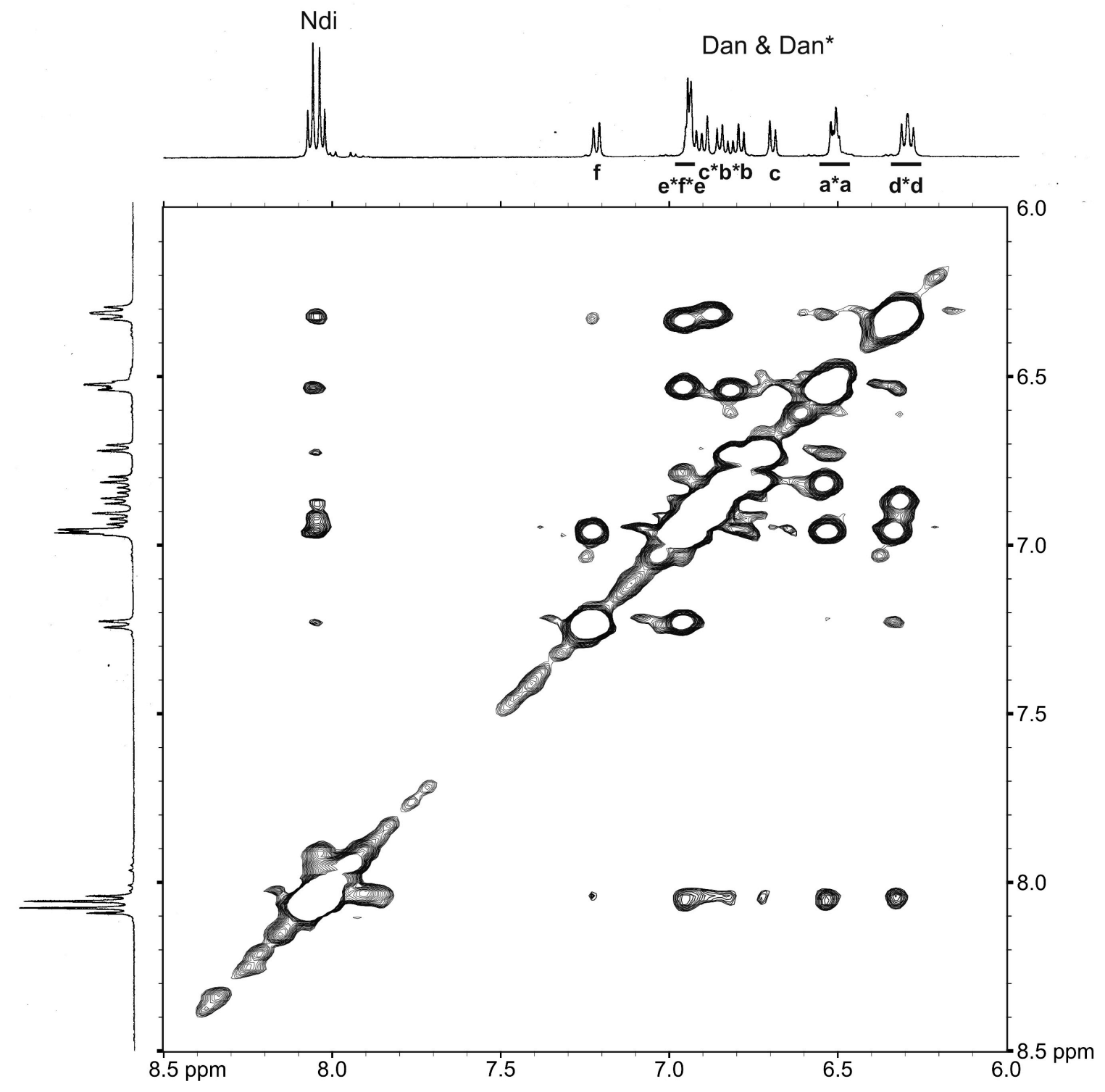

Figure 3S. Aromatic region of NOESY spectrum of $\mathbf{1 .}$ 
“AcHN-AspDanAspDan*AspNdiGly-OH " (2). (86\% yield) ${ }^{1} \mathrm{H}$ NMR (500 MHz, $\left.\mathrm{D}_{2} \mathrm{O}\right) \delta=8.07$ $(\mathrm{d}, J=7.5,2 \mathrm{H}), 7.99$ (d, $J=7.5,2 \mathrm{H}), 7.18(\mathrm{~d}, J=8.5,2 \mathrm{H}), 6.97(\mathrm{~d}, J=8.5,2 \mathrm{H}), 6.93(\mathrm{t}, J=7.9$, 2H), 6.85 (t, $J=7.7,2 \mathrm{H}), 6.80-6.77$ (comp, 4H), 6.75 (t, $J=8.3,2 \mathrm{H}), 6.64(\mathrm{~d}, J=8.3,2 \mathrm{H}), 6.55$ $(\mathrm{d}, J=7.5,2 \mathrm{H}), 6.36-6.32(\mathrm{comp}, 6 \mathrm{H}), 4.51(\mathrm{dd}, J=5.2$ and $3.6,1 \mathrm{H}), 4.37-4.30(\mathrm{comp}, 3 \mathrm{H})$, 4.27-4.23 (m, 1H), 4.05-4.00 (comp, 3H), 3.91-3.65 (comp, 11H), 3.62-3.58 (m, 1H), 3.47-3.42 (comp, 3H), 2.82-2.44 (comp, 11H), 2.40-2.35 (m, 1H), 2.13-1.95 (comp, 8H), 1.92 (s, 3H); ESI MS calcd for $\mathrm{C}_{69} \mathrm{H}_{74} \mathrm{~N}_{9} \mathrm{O}_{23}[\mathrm{M}]^{+} 1396.49$, found 1396.47 .

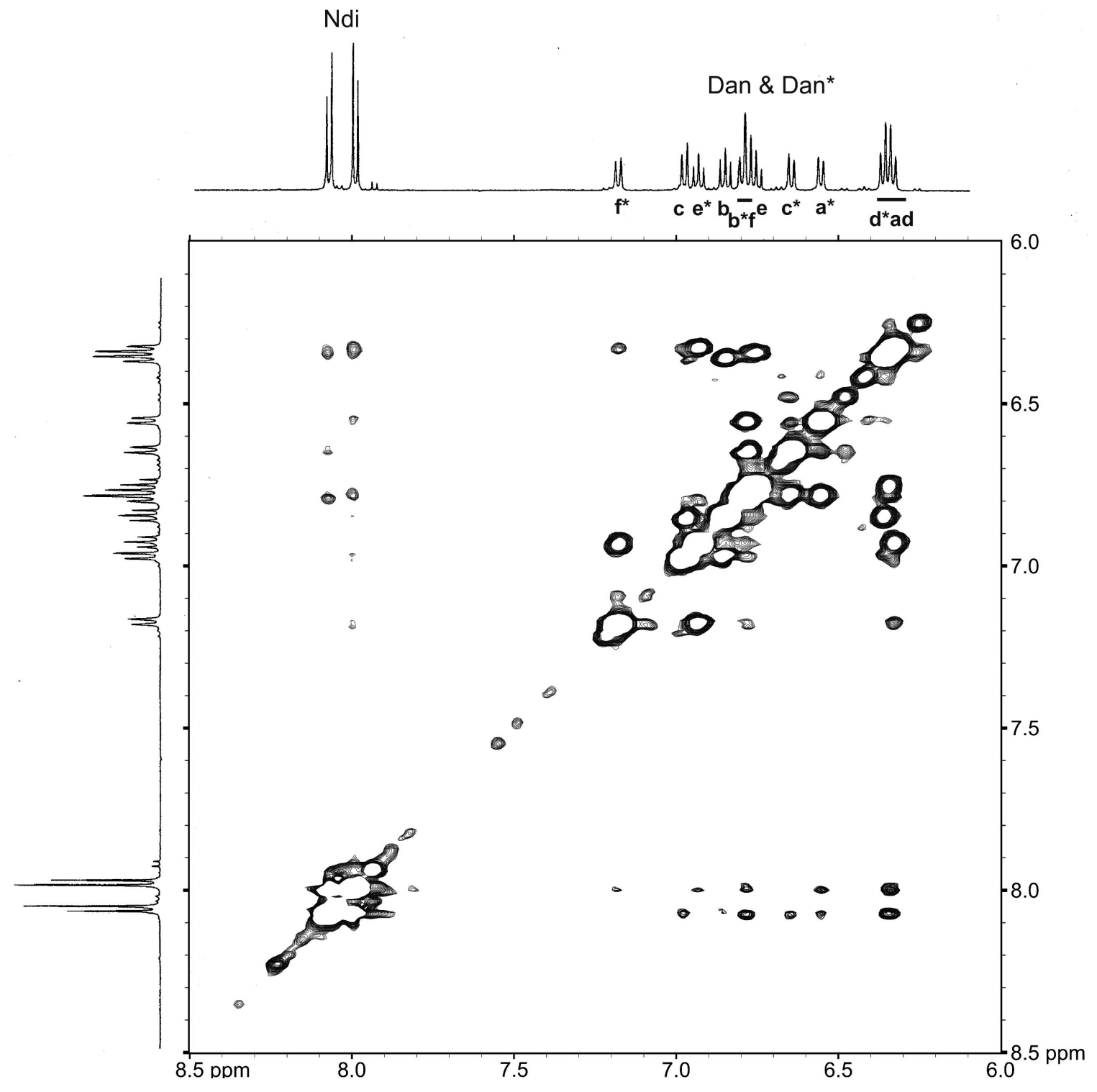

Figure 4S. Aromatic region of NOESY spectrum of 2. 
“SucHN-AspDanAspDan*(n=1) AspNdiGly-OH" (3). (84\% yield) ${ }^{1} \mathrm{H}$ NMR (500 MHz, D $\left.{ }_{2} \mathrm{O}\right) \delta=$ $8.03(\mathrm{~d}, J=7.6,2 \mathrm{H}), 7.77(\mathrm{~d}, J=7.4,2 \mathrm{H}), 7.49(\mathrm{~d}, J=8.8,2 \mathrm{H}), 7.21-7.19(\operatorname{comp} 4 \mathrm{H}), 7.14(\mathrm{t}, J=$ 8.2, 2H), 7.05-7.02 (comp 4H), 6.99 (t, $J=8.0,2 \mathrm{H}), 6.81-6.78$ (comp, 4H), $6.53(\mathrm{~d}, J=7.6,2 \mathrm{H})$, $6.47(\mathrm{~d}, J=7.8,2 \mathrm{H}), 6.33(\mathrm{~d}, J=7.4,2 \mathrm{H}), 4.63(\mathrm{dd}, J=5.4$ and 2.6, 1H), $4.54(\mathrm{~d}, J=2.2,2 \mathrm{H})$, 4.48-4.45 (m, 2H), 4.24-4.21 (comp, 6H), 3.79-3.70 (comp, 7H), 3.45-3.43 (m, 1H), 3.36-3.32 (m, 2H), 2.73-2.66 (m, 6H), 2.65-2.56 (m, 2H), 2.45-2.34 (comp, 4H), 2.27-2.18 (m, 2H), 2.001.91 (comp, 6H); ESI MS calcd for $\mathrm{C}_{67} \mathrm{H}_{69} \mathrm{~N}_{8} \mathrm{O}_{24}[\mathrm{M}]^{+}$1369.44, found 1369.46.

$\mathrm{Ndi}$

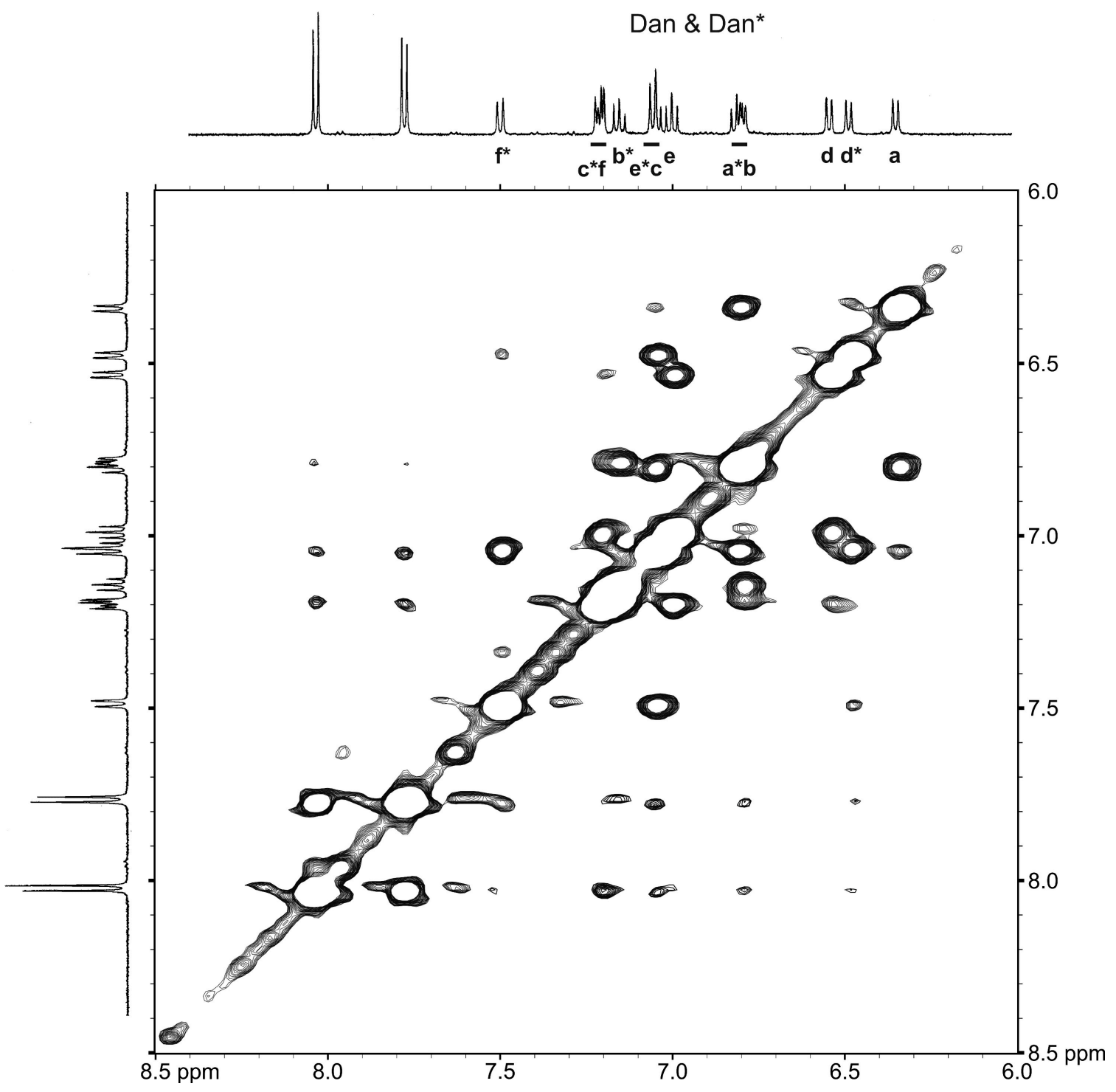

Figure 5S. Aromatic region of NOESY spectrum of 3. 
UV-Vis spectroscopy. UV-Vis spectra were taken on a temperature regulated Hewlett Packard 8452A diode array spectrophotometer. Concentration of stock solutions used for UV studies was initially determined by NMR integration of a known concentration of TSP- $d_{4}$ added to an aliquot.

Molecular modeling. Computations were performed with the HyperChem software using the MM+ force field (Hypercube Inc., $1115 \mathrm{NW} 4^{\text {th }}$ Street, Gainesville, FL 32601). A set of twenty random starting conformations of models for $\mathbf{1}$ and $\mathbf{2}$ was generated using unrestrained molecular dynamics at $1000 \mathrm{~K}$. Each of the twenty diverse structures was then allowed to anneal with a weak distance restraint as the simulation temperature was lowered from $1000 \mathrm{~K}$ to $300 \mathrm{~K}$ over 10 ps. For models of $\mathbf{1}$, this restraint was applied between the centers of the Ndi ring to each of the Dan rings which was reasonable based on the NOESY spectroscopy. For models of 2 the distance restraint was applied between the center of the Ndi ring and protons $\mathrm{c}, \mathrm{c}^{*}$ and $\mathrm{a}^{*}$ of the Dan units since these hydrogens displayed unambiguous crosspeaks. Even with these restraints in place, a wide range of aromatic-aromatic ring orientations resulted that were not particularly facecentered or even a Dan/Ndi/Dan stack. These alternative "stacking" geometries included many different edge-to-face arrangements all of which were significantly higher in energy than the most stably folded conformer. After annealing a final geometry optimization was performed without restraints using Fletcher-Reeves conjugate gradient, $0.01 \mathrm{kcal} \cdot \mathrm{mol}^{-1}$. The lowest energy conformer for both 1 (relative energy $\left.=-18.97 \mathrm{kcal} \cdot \mathrm{mol}^{-1}\right)$ and its sequence isomer $2(-19.27$ $\mathrm{kcal} \cdot \mathrm{mol}^{-1}$ ) afforded a structure that adopts a parallel Dan/Ndi/Dan stack. 